Revue de l'Institut des langues et cultures

d'Europe, Amérique, Afrique, Asie et Australie

24 | 2015

Lire et écrire ensemble

\title{
Mis escritores muertos, de Daniel Guebel: una pasión narrativa
}

Mis escritores muertos, de Daniel Guebel : désir de l'écriture, écriture du désir

Mis escritores muertos, by Daniel Guebel: A Passion for Writing

\section{Corinne Ferrero}

\section{(2) OpenEdition}

\section{Journals}

Edición electrónica

URL: http://journals.openedition.org/ilcea/3609

DOI: $10.4000 /$ ilcea.3609

ISSN: 2101-0609

Editor

UGA Éditions/Université Grenoble Alpes

Edición impresa

ISBN: 978-2-84310-313-1

ISSN: 1639-6073

Referencia electrónica

Corinne Ferrero, « Mis escritores muertos, de Daniel Guebel: una pasión narrativa », ILCEA [En línea]

24 | 2015, Publicado el 03 noviembre 2015, consultado el 20 abril 2019. URL : http://

journals.openedition.org/ilcea/3609; DOI : 10.4000/ilcea.3609

Este documento fue generado automáticamente el 20 abril 2019.

(c) ILCEA 


\title{
Mis escritores muertos, de Daniel Guebel: una pasión narrativa
}

\author{
Mis escritores muertos, de Daniel Guebel : désir de l'écriture, écriture du désir
}

Mis escritores muertos, by Daniel Guebel: A Passion for Writing

\section{Corinne Ferrero}

\section{How to do things with dreams: retorsión performativa y doble escena de la escritura.}

Ayer me dijo una amiga: "Soñé que te morías". Ahora, escrito, el "te" tiene algo de intencional: como si yo hubiese estado asesinándome en su sueño, suicidándome para que la frase se cumpliera.

Estoy en el bar "Varela-Varelita", en una mesa que es un reclinatorio, más allá, apenas en lo alto, en el altar de una columna, cuelga un retrato en blanco y negro de Héctor Libertella. (Guebel: 11)

Cómo hacer cosas con "sueños": así empieza el juego de Mis escritores muertos, con un sueño el de la muerte del narrador autodiegético- cumpliéndose, o queriéndose cumplir, en un íncipit ambiguo donde, como en la ciudad de Tandil donde transcurre gran parte del relato, "todo se mueve y tiembla" (Guebel: 20): la mesa en que se sienta el narrador-escritor es un reclinatorio, y el bar, o café literario Varela-Varelita, una suerte de templo cristiano ${ }^{1}$ donde se difuminan los confines del sueño, y que estremece de entrada este primer soporte enunciativo, afianzando y socavando la escena genérica de la escritura íntima (o diarista), tejiendo y destejiendo su tópica²

2 Posado en "el altar de una columna" de este bar-santuario, el retrato en blanco y negro del escritor real Héctor Libertella es primero una imagen fascinante que parece atraer a sí a un narrador-escritor pronto a volverse sombra entre las sombras de su propia maquinaria fantástica, precipitando su devenir fantasmal e inmortal ${ }^{3}$.

Me mira. Las dos manos alzadas. Por un momento parece que estuviera pensando en impartir una bendición, pero los índices van hacia abajo, dirigidos a golpear el teclado: Héctor es el segundo escritor que se "me" murió. (Guebel: 11) 
Interrumpiendo el hilo del relato retrospectivo y congelando en un presente intempestivo esta primera escena -y lugar de enunciación privilegiado del escritor-diarista-, el retrato de Libertella distingue ("Me mira"), y a la vez petrifica un narrador detenido en su avance por "las dos manos alzadas" y los índices amenazantes del escritor muerto. El gesto es tan intimidante como intimante: el narrador-escritor es un cadáver, como cada vez que se resucita el cadáver del lector que cada uno es (Libertella: 237), una estatua de sal congelada en el inframundo del recuerdo, fulminado por mirar atrás en ese momento de terror que también precede y vuelve posible la escritura4. "Héctor es el segundo escritor que (se) "me" murió": y la voz narrativa un estertor, un éter muy sutil empañando apenas ese pronombre cuasi reflejo ("se") que bordea el confín de la muerte de su precursor del propio asesinato soñado-anunciado al principio ("Héctor [...] "me" murió"). El sueño ha extendido la sombra de las tinieblas de la muerte, y, como si conspirara con las engañosas ilusiones del sueño ${ }^{5}$, el narrador de Mis escritores... puede realizar la propia desaparición soñada por otro, asesinarse "para que la frase se cumpl[a]" (Guebel: 11), abriéndose paso también con ese morir "la posibilidad de escribir un libro nuevo". (Libertella: 237)

Si "soñar algo es hacer algo", es también decidir así lo que es real y lo que es la realidad, desde la misma irrealidad del sueño. Realizada esa extraña performance narcótica que abre el texto a la convivencia de elementos opuestos -o, según los términos de Blanchot, a la " unidad de incompatibles" (2002: 25)-, nace entonces una singular "ficción en la fisión" (Libertella: 240): un relato que juega una doble escena, operando siempre en dos lugares absolutamente distintos y contradictorios, entre el sueño y la vigilia, lo visible y lo invisible, el inframundo nocturno y el mundo de los vivos por donde transmigran los fantasmas de dos escritores reales, Jorge Di Paola y Héctor Libertella.

\section{Una pasión por la noche}

En estas páginas no quise narrar los últimos días de dos escritores a cuyas agonías no asistí, sino entender el sentido de una experiencia de la que no puedo sustraerme. [...] Cuando leo, imagino que lo hago con los anteojos de Libertella; cuando escribo, lo hago para que él me lea. (Guebel: 61)

En Mis escritores muertos, la forma de ese sentido homenaje también es doble: más allá de contribuir en asentar la escena genérica de la escritura autobiográfica ${ }^{6}, \mathrm{y}$ de constituir in fine el tema ${ }^{7}$, o pretexto, de esa obra, el homenaje se convierte en el espacio de una doble experiencia singular del escritor con la muerte. La noche en que transcurre el homenaje a Di Paola en Tandil - remembranza que constituye la parte visible de esta obra- es también la noche por donde se filtra el fantasma de la literatura aprisionando al escritor en su "red sonora" 8: en ese lugar de la filiación y de la interpelación, la remembranzahomenaje es también una obsesiva combinatoria de la distinción y del tributo, y el duelo un medio -o médium- agónico en que se van dignificando los acordes de una voz singular: una "operación literaria."

“[...] despego los labios para decirle a la morena la verdad estricta y definitiva sobre mi ser, lo único cierto que hay en mí, el amor por mi hija y mi pasión por la literatura. [...] lo que hice o quise hacer con los pocos o muchos libros que escribí y publiqué a mi propia sombra o tratando de remedar la luz de otros (de Libertella y Di Paola desde luego, pero la lista podría ir ampliándose, es el entusiasmo por las influencias...), eso sí puede ser dicho" (Guebel: 30-31)

En la "operación fracturada de lectura" que define para Libertella la escritura -o lectoescritura- se requiere establecer cercanías y distancias con la tribu, o toda una 
tradición local de lecturas en las que el escritor -intruso o entrometido- se sabe atrapado, "apenas un Golem armado de determinada manera por las letras de otros", el "viejo fantasma de la literatura" del que cuelgan sus obras-collares (1993: 214, 237). Para el único sectario de su secreto, de "la verdad estricta y definitiva sobre [su] ser" en relación con la literatura $-\mathrm{y}$ sus fantasmas-, esa revelación, a lo largo de la Mis escritores muertos, no se produce, o para retomar las palabras de Genette sobre Borges, es "la inminencia de una revelación que no se produce" (1966: 132): en la cadena de relatos engarzados que constituye este libro, el ser de la literatura se presenta primero en boca del narrador como un artefacto, o un cuerpo, un "sistema de relaciones [...] inerte y seco" (Guebel: 14), absolutamente inmanente. Retomando el hilo de esa metáfora corporal, la cifra de ese secreto del arte de narrar podría buscarse entonces en el espíritu de los difuntos - "el entusiasmo [de] las influencias"- que, literalmente, insuflaría esa letra inerte imprimiéndole no tanto un sentido, o la marca de un legado, como una tensión, un movimiento circular e infinito: el que figura oportunamente el ritmo fisiológico de la respiración. Metáfora privilegiada del espíritu (o de la vida espiritual) en la tradición filosófica occidental, la doble corriente inversa, vital y contradictoria de la respiración (que une y opone inspiración y expiración, contracción y extensión) parece imponer también sus pautas, y su ritmo a la escritura de esta novela.

7 Veremos así cómo, en una versátil "política del tributo" consistente en ensalzar y desatender un legado, pregonar y deshacer la propia estética, el narrador de Mis escritores... es a su vez una "pura tensión lírica" (Libertella: 13) debatiéndose entre los contrarios como entre las pasiones discordantes del alma y del cuerpo, y convirtiendo esa metafísica espiritual dualista en base estructurante de un relato cuya mecánica contradictoria encripta también, como trataremos de mostrarlo, el principio vital: la poiesie y la potentia.

\section{El elogio de la forma}

El primero de "mis" escritores muertos fue Jorge "Dipi" Di Paola. A Dipi lo conocí en el bar La Paz. [...] Su novela Minga! preanuncia (o quizá vuelve innecesario, epigonal, puramente ilustrativo) el estado de fisión al que aspira la mejor literatura contemporánea: disolución de la identidad del personaje y puesta a punto de la narración como recuento de destinos sometidos a combinatorias de series improbables. (Guebel: 11-12)

Después de la evocación del recuerdo de su primer encuentro con Di Paola -cuya descripción rescata esta vez del cristianismo la figura algo transformada de un mesías " misógino-apostólico" (Guebel: 12), apuntando de entrada a la actio in distans de la mujer en esta obra simuladora y seductora ${ }^{10}$ - el narrador se detiene en la ponderación de la poética del primero de sus escritores muertos en un doble movimiento contradictorio: mientras se niega a desempeñarse como lectoescritor crítico de las obras de Dipi -“Dejo a otros la exégesis de esa obra; la crítica no es mi fuerte" (Guebel: 12)-, emprende sin embargo conjuntamente el análisis pormenorizado del legado del maestro en una exégesis que, además, contradice, o desestabiliza insensiblemente, los principios estéticos ensalzados y la fórmula que, para el narrador, "une a Dipi con Libertella: el acto de escribir sin reservas ni ocultamientos" (Guebel: 13). En el curso de un comentario valorando implícitamente el paradigma de la autonomía y del autotelismo de un texto literario liberado de la sujeción a una conciencia creadora y de la ilusión de su trascendencia, el narrador confiesa no obstante pretender siempre "exhumar" en sus lecturas, o relecturas, "el alma del autor", 
preludiando de alguna manera la propia aplicación sistemática de la refutada "teoría del iceberg" vilipendiada y sin embargo devotamente puesta en práctica en cada uno de sus relatos posteriores. En un elogio del formalismo y del ser "inerte y seco" de la literatura (entendido como la combinatoria de "un sistema esquelético") literalmente habitado por palabras pertenecientes al campo semántico-léxico de la muerte y de la resurrección (" exhumación", "fantasma", "alma", "transparencia", "espiritual"), el narrador de Mis escritores aparece como un escritor tironeado entre la inmanencia o la literaridad del arte impersonal que pregona y la trascendencia de una experiencia literaria cuyo secreto habría de buscarse en el alma de su autor, en lo más recóndito y secreto del yo profundo del creador (Guebel: 13-14). La terminología cristiana utilizada para describir la labor del escritor ("profeta del asunto") y su "dedicación" al arte de narrar ${ }^{11}$ instala también esta escisión teórica inaugural en el dualismo característico de la antropología medieval y clásica -spiritus versus caro- enfatizando a su vez la fractura entre una letra muerta y la letra viva que anima el espíritu divino ${ }^{12} \mathrm{e}$ imprimiendo al relato una tensión permanente entre los contrarios del alma y del cuerpo, de lo oculto y lo visible, lo secreto y lo manifiesto.

Hay una ecuación, más bien una economía, que en primera instancia atribuye el valor de un cuento a la importancia de la revelación proporcionada por la palabra o la frase final. [...] La teoría del iceberg sostiene que la narración escrita es la emergencia visible de una historia subyacente, ominosa o conmovedora, que carga con la riqueza de lo apenas sospechado. [...] el hielo que se esconde bajo la línea de la superficie de la página, es una masa de sentido -un volumenincomparablemente mayor que aquella que emerge. [...] Pero tal elevación cognitiva [...] formaría parte de la mística, que es un mero progresismo teleológico, y no de la literatura." (Guebel: 13)

9 La nota marginal destinada a concluir y asentar la exégesis contradictoria de la poética de Di Paola y de su cuento "La forma", propone ahora una crítica de la teoría del cuento como artefacto, y más precisamente de "la teoría del iceberg". A contracorriente de la poética tradicional del cuento y de su eficacia narrativa -según la cual "un relato visible esconde un relato secreto" y el cierre de todo cuento constituye su revelación sorpresiva, el momento en que ésta "aparece en la superficie" (Piglia: 106)-, el narrador de Mis escritores... arremete contra "esta teoría de lo visible y lo oculto" sospechosa tal vez, in fine, de convertir la literatura en el instrumento de la revelación de alguna verdad, del sentido o del sinsentido de la existencia ${ }^{13}$. Conforme el primer vaivén introducido entre el espíritu y la materia por nuestro lectoescritor renuente-dispuesto, el relato proseguirá entonces engendrándose como por el impulso de la misma contradicción: preludiando el enigma del Tandilito -doble persecución "misógino-apostólica" del monstruo subacuático y del secreto de la mujer, y caso extremo de insubordinación de lo ficcional a lo teórico-, otro relato ilustra de nuevo esta tensión, verdadera conmoción, entre los dos polos opuestos de lo inanimado y lo inerte. En el salón de actos de Tandil, las zozobras literarias y sentimentales (o eróticas) de un narrador empeñado en hacer aflorar a la superficie su verdad profunda - a contracorriente de la propia teoría profesada a la sombra de Di Paola - pueden leerse también como la odisea de un alma en pena de la armonía, o de la unidad entre su adentro y su afuera, su reflexión y su expresión. Un espíritu inquieto perdiéndose y reencontrándose en la letra de su obra. 


\section{Las pasiones del alma}

10 "La verdad se esconde en la trama de los hechos, me discute Joseph Mengele desde una película" (Guebel: 19). Cínica y trágicamente amparado en las palabras de Joseph Mengele -que reinstalan la voz narrativa en los confines de la muerte y de la ausencia dramatizando la tensión entre espíritu y materia- el relato se centra ahora en el recuerdo de un último encuentro acaecido en Tandil con motivo de un acto de homenaje organizado por la ciudad natalicia del autor.

Ya se había hecho de noche cuando llegamos al suburbio donde, entre el frío que se colaba por todas las aberturas de una gran carpa blanca, fuimos a sentarnos en el puesto de la editorial que había publicado mi novela, otra. Durante hora y media esperé, y esperé por el Lector, mientras que a metros apenas crecía la fila de compradores de la nueva obra de un dietólogo con nombre de flan sintético: el doctor Máximo Ravanna (En Tandil todo se mueve y tiembla). [...] Al atravesar el pasillo me doy cuenta de que la sala donde se realizó el evento se continúa en la carpa blanca donde la noche anterior el doctor Ravanna firmó su pacto con la delgadez. La carpa de la feria es su continuidad o reverso [...] ¿Correrán por las sombras las cosas inertes, en Tandil? (Guebel: 20-24)

11 A una escenografía desconcertante del límite inestable, la desunión y el vacío, corresponden ahora una cronografía nocturna y un lugar de enunciación -el salón de actos de la feria del libro donde se celebra la ceremonia-cuyos vacilantes y movedizos contornos parecen prolongar el largo paréntesis del sueño abierto en el íncipit, conspirando a su vez con el irreversible desvanecimiento del narrador de Mis escritores muertos. Privado del evento singular de la firma y del momento simbólico de la inscripción y atestación de la propia obra ${ }^{14}$, el escritor que espera sentado durante la ceremonia de deposición de autógrafos es una presencia fantasmal sin lectores, y el único de los presentes en el acto de homenaje a "la gloria" de Di Paola del que no se transcriben los escritos ni las palabras, sino las "ganas de incinerar lo que redact[ara] para la ocasión" (Guebel: 23): un deseo de consunción y desvanecimiento que abre paso en el relato al íntimo desasosiego de un alma tratando desesperadamente de objetivarse, o recogerse, en sus manifestaciones. En este afán especulativo - entre trágico y cómico-de reunificación del narrador consigo mismo, veremos que se trama también el motivo, o la unidad melódica y nostálgica de una escritura de la ausencia y la discordancia.

No obstante, alzo de nuevo esa mano para soltar mi advertencia, y al hacerlo mi cuerpo produce un movimiento en falso [...] alcanza para que se rompa el sillón sobre el que estoy sentado, que es el taburete que corresponde al mismo piano donde a principios del siglo xx, en el extremo más inhóspito de una gira mal programada, Vera Ivanovna ejecutó devotamente Vers la flamme, sonata de su ex marido Alexander Scriabin. Estallido de las maderas, desgarro del terciopelo rojo, desparramo del relleno, salto de los resortes. [...] El ruido de rotura es sórdido, rastrero." (Guebel: 27)

En el curso de una conversación con una de las mujeres de la asistencia, el lector asiste a una espectacular e irresistible caída del narrador que se produce en el momento en que éste, al constatar que la mujer concuerda completamente con sus opiniones, decide “ corregir [sus] afirmaciones" anteriores a riesgo de perder "lo que hasta entonces prometía como una noche de placeres... a los que por otra parte había renunciado hacía apenas unos momentos, $y$ porque sí." (Guebel: 27). El tiempo de la caída -que empieza con la rotura del asiento, cuando el mismo narrador fomenta la discrepancia, o la desunión con la mujer-cubre el 
del relato del interminable intento de explicitación de sus argumentos y de revelación de su "verdad oculta" (Guebel: 31). Para quien recuerda que el lugar del homenaje es también la continuidad, o reverso, de la carpa donde la noche anterior "el doctor Ravanna firmó su pacto con la delgadez", la señal es clara: aquí, al contrario del Fausto de Goethe, "lo eterno femenino" no atrae a lo alto, y el Eros se vuelve una potencia unificadora siempre contrariada por el peso de la muerte en el deseo ${ }^{15}$. El narrador desagarrado entre dos impulsos contradictorios - "cuando alzo la mano del adiós - ¿y por qué irme en vez de quedarme?" (Guebel: 25) - se vuelve el testigo impotente de la desunión entre sus actos y su íntima voluntad, y aparece literalmente tironeado entre los contrarios de su ser, como entre las dos partes de su alma apetitiva y racional, entre el amor sublime y la concupiscencia (cupiditas versus caritas): "[...] lo que recién había desdeñado se vuelve inmensamente tentador, y el miedo a perderlo me perturba. La lujuria y el sentimentalismo van juntos y piden su libra de carne" (Guebel: 27). Presente en cada momento del incidente, la amenaza de la muerte ${ }^{16}$ enfatiza el motivo de la desunión (Eros bajo la ley de la indigencia y la penuria), y convierte esa caída en un interminable descendimiento a las profundidades del infierno que subraya humorísticamente la alusión extemporánea al sillón donde Vera Ivanovna -viuda desconsolada de Alexander Scriabin, músico desgarrado en busca del "bien supremo" y protagonista de la novela $E l$ absoluto ${ }^{17}$ ejecutara, la pieza Vers la flamme (o hacia las alturas celestes del Espíritu ${ }^{18}$ ) en memoria del desaparecido.

"[...] cuando yo entro en contacto con las baldosas frías, mi pantalón se rasga, el efecto de estilo es siempre un subrayado." (Guebel: 32$)$ : antes de llegar al estrepitoso acmé del desagarro y la desunión del ser, el descenso del narrador es la ocasión para verificar que el duelo de la unidad de los contrarios se manifiesta también a través del divorcio entre el fondo y la forma de su discurso.

Puedo objetar eso y muchas cosas mientras sigo cayendo, objeciones que no por ciertas dejan de ser obvias y que fluyen tan rápido por mi mente que soy incapaz de articularlas bajo la forma de una exposición completa y razonada, primero porque entre idea y expresión hay una distancia insalvable, no existe nada que se parezca a una trasposición inmediata [...] lengua y pensamiento discurren en dimensiones distintas, si se cruzan es por casualidad [...] cuando hay cruce y traducción el pensamiento va a pérdida. (Guebel: 30 )

Presa del mismo delirio que identificara Barthes en la relación lingüística de los hombres a la realidad -las palabras no son sino "expedientes verbales" que reducen, deniegan o asumen "la inadaptación fundamental del lenguaje y de lo real" (1989: 19) - el narrador experimenta a su vez esa inadecuación elemental en el curso de su descenso: oponiendo al movimiento de su caída la reconstitución inversamente ascensional del razonamiento de uno de los presentes (E.M.-B.) sobre la abdicación de los autores que transigen con las leyes del mercado, emprende también en este doble viaje a la semilla de un discurso ("voy del final de su frase hasta el inicio [...]") y de la esencia del arte, la inquieta indagación del punto de coincidencia perfecta entre sus ideas y su expresión. Mientras discute una argumentación con la que reconoce, in fine, compartir los presupuestos ("en el fondo sé que E.M-B. tiene razón"), el narrador de Mis escritores... bien parece lamentar también con este divorcio entre lo pensado y su manifestación, la imposibilidad del acceso del sentido silencioso a la palabra sensata, su imposible conversión en un discurso articulado: la escisión trágica del sentido y de la realidad. 


\section{Noli me legere}

[...] en este momento yo no soy más que un envase estremecido por miedo a la aniquilación [...] quizá ese secreto que quiero forzar sea la clave de mi arte [...] en lugar de la palabra definitiva suelto a ritmo de ametralladora una sucesión de imbecilidades: es como una lanzadera que me sostiene en el aire [...] la sucesión sintáctica es perfecta aunque el concepto sea nulo, y es precisamente en el momento en que el vacío, la nadería de mi exposición encuentra su ápice, la absoluta perfección de la palabra hueca, cuando yo entro en contacto con las baldosas frías [...]. (Guebel: 31-32)

Impedido de aflorar a la superficie de su discurso, el inaudito secreto del arte del narrador atesta a su vez que el silencio y la palabra han cesado de conferir, que la cifra está perdida: la expresión no retiene la reflexión de donde emana, y ésta es el "envase estremecido" y sin sustancia de una manifestación informe. Finalmente, el término de la larga caída "rastrera" del narrador coincide con el cénit de la revelación de ese secreto, y ésta a su vez, con la nada, "el vacío". "Dí tu palabra y rómpete": en la consumación simultánea de la ruina temporal y espiritual del narrador, aparece y desaparece a un tiempo esa verdad profunda cual sol divino que se eclipsara en su propia visión ${ }^{19}$. En esa tensión mantenida entre la elevación y la caída, la forma y el fondo, el momento final de la exposición de la "nadería", o la "absoluta perfección de la palabra hueca" -el solsticio insostenible de la verdad- confirma también sin duda que, si "hasta lo que se oculta [...] está a la vista" (Guebel: 13), escribir no puede ser sino "traer a la superficie algo como un sentido ausente" (Blanchot, 1980: 71).

Quien se consagra a la obra es atraído hacia el punto en que ésta se somete a la prueba de la imposibilidad. Experiencia específicamente nocturna, experiencia de la noche. [...] allí el que duerme no lo sabe, el que muere va al encuentro de un morir verdadero. [...] La pasión por la noche, solo el día la puede experimentar. [...] en ella comienza lo que va a llegar a ser su propia pasión, su más alta paciencia, su residencia infinita en la muerte. (Blanchot, 2002: 15)

La Caída y la desaparición simbólica del narrador de Mis escritores... -cuya condición fantasmal es desde el principio intrínsecamente ligada a la posibilidad de escribir-invita también a considerar la condición paradójica de la escritura tal y como se expone en el espacio órfico del desobrar de Blanchot. "Hablar poéticamente y desaparecer": el llamado de Orfeo a "morir más profundamente" hace de la experiencia de la muerte el punto crítico donde se borra "la falsa certeza del ser" (2002: 143). El poeta, o el escritor consagrado es entonces el que pone a prueba la misma obra (y el mismo ser) en la ausencia de las seguridades protectoras del sentido y del ser. "De una vez por todas / Es Orfeo, cuando hay canto. Va y viene." (2002: 143): a su vez, esa "experiencia de la noche" (el des-astre en tanto alejamiento del Astro, o de la verdad) que condiciona la escritura genera un movimiento de creación como proceso de transformación incesante, en términos de Blanchot: "el movimiento infinito de morir [...] donde del no-ser se regresa eternamente al Ser" (2002: 143).

Para dar también fe del carácter tragicómico del largo descenso del narrador a los infiernos $-\mathrm{y}$ de la tensión entre gravedad y humorismo que caracteriza toda la obra-, podríamos volver al Eros, a su potencia unitiva y su doble condición de vida y de muerte (de plenitud y penuria), y recordar que es sin duda porque el deseo es indigente que ha de ser ingenioso (Lyotard: 26): así, en la larga noche de la persecución del monstruo subacuático de Tandil y de las profundidades del Ser, el motivo de la desunión (entre lo animado y lo inerte, el secreto y su manifestación, el hombre y la mujer) genera a su vez 
un relato que, como la piedra movediza de Tandil, se desata, rueda, peregrina, se abre y crece mutando de un estado a otro, de un cuerpo a otro. En el deseo de la unidad, la unidad de un deseo.

\section{El Tandilito y el enigma de la mujer}

18 "Un rato más tarde estamos, Bizzio, E.M.-B., la morena, otra mujer (una rubia) y yo, en la camioneta de E.M.-B." (Guebel: 32). En la oscuridad de la noche y del bosque que bordea el lago de Tandil, el narrador soñoliento ${ }^{20}$ y sus acompañantes emprenden ahora -entre conversaciones y cuentos autogenerados por la excitación sexual de los presentes (el deseo y su potencia unificadora) - un recorrido en que la sombra del Tandilito, el monstruo que habitaría las profundidades del lago, irradia primero un misterioso resplandor sobre los arcanos de lo femenino.

Ella no solo piensa algo distinto de lo que está diciendo, sino que sin decirlo, se las arregla para transmitírmelo. [...] la trama misma de sus palabras están dando lugar a una especie de argumentación segunda, coexistente con la primera, una especie de tejido contrapuntístico al modo de los coros medievales [...] cada mensaje cifrado tiene su propio sistema de desciframiento, así que solo se trata de empeñarse en la tarea: la criptología es el arte nuevo de los trovadores para ingresar en la selva espesa de la mujer. (Guebel: 34 )

Entre las dos mujeres presentes en la camioneta se establece de entrada una doble relación de oposición y de complementariedad: mientras el personaje de la morena aparece como un ser fracturado entre sus propias palabras insulsas y sus pensamientos profundos, el personaje de la rubia, "que lleva la voz cantante", es caracterizado por "la estupidez incomparable" de su conversación (Guebel: 35). No obstante, su voz -que se desplaza progresivamente de personaje a actante de la enunciación ${ }^{21}-$ se convierte pronto en el contrapunto del alma de la morena: la tensión estructurante entre lo visible y lo oculto se desdobla ahora en una extraña oscilación entre el silencio de una y las palabras de la otra. La reserva de la morena se vuelve así el alma, o el principio de conmoción de las palabras de la rubia, las cuales cuentan "aquello que la morena nos quiere comunicar, con la manera indirecta que debe asumir toda información verdadera" (Guebel: 36). Entre los dos pares contrastados de la rubia y de la morena, podría tratarse entonces para el lector criptólogo de restablecer o recomponer los elementos dispares de la entidad femenina: el decir y el pensar, la voz y el silencio, el adentro y el afuera de la mujer. De hecho, el misterio que ocupa al narrador durante la primera parte del viaje es la posibilidad, desde el asiento de conductor, de orientar discretamente el retrovisor hacia la mujer para escrutar "los secretos de su entrepierna y sab[er] algo de ella, por fin" (Guebel: 35): en esta operación de conocimiento declarada imposible para las propias mujeres impedidas de "obrar al mismo tiempo como sujeto y objeto de conocimiento [...] [y] de estudiar la interioridad de sus interioridades" (Guebel: 35) - se alude de manera apenas velada al enigma de la mujer, o de la sexualidad femenina (incompleta) en la teoría freudiana, en particular al horror que provocan los órganos genitales de la mujer por el miedo inconsciente a la castración (ni la muerte ni el sexo de la mujer pueden mirarse de frente ${ }^{22}$ ). Más aún, cabe pensar que esta insistencia en la impotencia de las mujeres para acceder a su propio enigma se refiera también al carácter falocéntrico (y falocrático) de esta obsesión en la perspectiva freudiana: antes del arte nuevo de "la criptología", el psicoanálisis, además de pensar la mujer como simétrico desvalido del modelo masculino, también inventa - para remediar al silencio y al pudor impuestos por la represión sexual- 
la idea de un secreto femenino por desvelar, o forzar, en la cura $^{23}$. La palabra que se libera ${ }^{24}$ es al mismo tiempo la que se subordina a la palabra, y a la verdad del otro, el analistamaestro: la verdad es lo que ha de des-velarse, y por lo tanto, no es sino una ilusión metafísica de la profundidad, de la existencia de un falo disimulado detrás del velo. El enigma de la mujer es una ilusión fetichista del hombre, y "es el paradigma de todo enigma". (Kofman: 104)

Suerte de preludio a la persecución de otro ente monstruoso, el Tandilito, este breve excursus misógino arroja de entrada sobre la Verdad de su ser -oportunamente encarnada en el relato por la voz de una mujer, la rubia- el movimiento femenino y seductor del velo, "el placer de la disimulación" (Derrida: 54): lanzado, a fondo perdido, en la persecución de lo oculto tras las apariencias, el relato progresa entonces forjando y derritiendo a un tiempo la ilusión de los trasmundos, forzando y velando un secreto que fabrican y esconden los sectarios. (Carrera: 18)

\section{La sirenita y el Jörmungandr}

El cuento de la rubia: durante siglos, milenios, la Piedra Movediza de Tandil permaneció en su lugar, una mole esferoide que oscilaba sobre su base enclavada en una saliente de la montaña. [...] Un día [...] para ilustrar a sus hijos acerca de la veracidad de la leyenda [...] un padre colocó una botella de vidrio en el espacio situado entre la base levemente convexa de la piedra y su punto de apoyo. Al fin de la semana volvieron: la botella había estallado en fragmentos. La piedra se movía. Establecido esto, comenzó el reinado del terror. [...] (Guebel: 37)

21 Ser doble dotado de branquias y pulmones, a la vez mamífero y carnívoro, el monstruo nacido de la piedra-huevo inmersa en el fondo del lago de Tandil revela un buen día su presencia absorbiendo de un bocado el bote de la familia del contratista Rogelio Ambassi. Aplicando a la letra la refutada teoría del cuento consistente en crear un efecto de espera y de tensión hacia un final sorpresivo, el relato suspende ahora la revelación del enigma del monstruo subacuático del hilo de la investigación de los "buzos tácticos" de la Policía Federal (Guebel: 42). Para obtener que éste salga a la superficie $-\mathrm{y}$ convertirlo en atracción turística-, las soluciones encontradas consisten en colgar piezas de carne primero, y luego obras conceptuales compuestas de los órganos internos de los artistas, en una exposición al aire libre que se vuelve el motivo para una digresión -una sumasíntesis- sobre la mutación del arte en los últimos siglos ${ }^{25}$. Empeñado en permanecer invisible y aparecer ex abrupto para devorar algún paseante, el monstruo es perseguido mediante nuevas soluciones drásticas.

El intendente decidió obrar con energía: el lago fue vaciado en un santiamén, pero en el fondo no se encontró nada más que la roña de siempre. También se realizaron batidas de caza, tratando de verificar si la alimaña se había escondido en algún rincón. [...] Pero la bestia no apareció. (Guebel: 51)

De nuevo, el suspense es una decepción: el narrador no coincide con su verdad profunda, y el "alma de la Piedra" (Guebel: 38) no se reúne nunca con su masa, la bestia no aparece. De nuevo, el relato trabaja y modela la forma de esa discontinuidad, como un eterno regreso nostálgico a la conjuración originaria del cuerpo y del mundo: y escribir, según las bellas palabras de Arturo Carrera, es entonces "rozar esta parte de misterio; buscar esa luminosidad disipada que no nos escindía” (1993: 16).

En el último de los relatos engarzados de esta historia, el narrador autodiegético retoma la palabra y, como despertando de una largo sueño, relata su encuentro final con la 
morena que se revela, en la intimidad, ser un monstruo marino, a todas luces el mismo Tandilito. Al término de la evocación por el narrador de su recuerdo del cuento de la sirenita de Andersen, el lector entiende qué otro secreto se fue tramando, no "en la carroña del fondo", sino en la superficie, o en el "tejido contrapuntístico" (Guebel: 34) de esta novela: “- ¿Quién es el monstruo? - digo?" ${ }^{6}$ (Guebel: 57)

Nadie notó que de un tiempo a esta parte se habían verificado ciertas variaciones de la densidad de su masa acuática, ciertos movimientos a contracorriente, como si algún organismo voluminoso y potente estuviera desplazándose por sus profundidades [...] En palabras de la rubia, estos movimientos indicaban el proceso de crecimiento del Ser, que debía estar desarrollando su aparato respiratorio anfibio (mitad branquias, mitad pulmones) y alimentándose con la carroña del fondo [...]." (Guebel: 40)

El secreto de la esencia del Ser está guardado afuera: en el lugar que hay que reinventar. La transformación y el proceso de crecimiento del narrador-monstruo de Mis escritores... señalan así el tempo, o el ritmo fisiológico (o neumológico) de una escritura: el contrapunto permanente de disimulación y manifestación, contracción (sistólica) y extensión (diastólica). Esta contracorriente espiritual es también la potencia unitiva de dos movimientos contrarios -siempre co-presentes el uno en el otro, y ordenándose el uno al otro-: respirar, existir, es la busca infinita de este punto de coincidencia. Escribir, un movimiento infinito de regeneración y transformación que firma la invisibilidad que desvela. Volviendo a la poética del cuento como artefacto, el lector devoto de su "credo para buzos" (Guebel: 13) encontrará que el secreto, o la clave del arte del escritor de Mis escritores... no se esconde sino en la propia trama del relato bajo la figura de otro monstruo, el Jörmungandr -o Uróboros ${ }^{27}$ (el título inicial de esta novela) - que sí se esconde debajo del mar... "A la serpiente, Jörmungandr, la tiraron al mar que rodea la tierra y en el mar ha crecido de tal manera que ahora también rodea la tierra y se muerde la cola.". (Borges: 707)

La sirenita no dudó. Agitando por última vez su hermosa extremidad verde ascendió a la superficie y apenas volvió la cabeza hacia abajo, con un dejo de nostalgia [...] No hay palabras para contar el dolor de su mutación, el lento desgarro de su materia hasta obrar la alquimia esperada. [...] Pasan meses. El príncipe, perdido en las exigencias de su histeria cruel, su propio encantamiento, ignora el sacrificio de la ex sirena, en la que además ni repara, y tampoco se entera de que para ella caminar es un tormento. El dolor del amor a cada paso, hasta el fin y sin consuelo... [...] El cuerpo es su autobiografía. (Guebel: 56)

Atraída al reino de la luz por la mirada ausente de un príncipe displicente y espectral, la sirenita del "perverso cuento infantil" de Andersen figura sin duda en su pervertida ascensión transgresiva y el doloroso sacrificio de su metamorfosis, el carácter absoluto, paradójico y trágico de la llamada del arte. Gestándose en el duelo de la unidad y desgarrándose en la secreta exacerbación de la esencia, como un alma eternamente en pena del "verdadero lugar" (Carrera: 16), entre la vida y la muerte, el olvido y el recuerdo, el deseo y el amor, un texto conspirando un punto de fuga: el espíritu de una fuga. 


\section{BIBLIOGRAFÍA}

BARTHES Roland (1989), Leçon, Paris : Seuil.

BLANCHOT Maurice (2002), El espacio literario, Madrid: Editora Nacional.

BLANCHOT Maurice (1980), L'écriture du désastre, Paris : Gallimard.

BORGES Jorge Luis (1989), Obras completas, Buenos Aires: Emecé.

BORGES Jorge Luis (1991), Obras completas en colaboración, Buenos Aires: Emecé.

CARRERA Arturo (1993), Nacen los otros, Buenos Aires: Beatriz Viterbo Editora.

DERRIDA Jacques (1978), Eperons, Paris : Flammarion.

DesCARTES René (1977), Meditaciones metafísicas, Madrid: Alfaguara.

GeNETTE Gérard (1966), Figures I, Paris : Éditions du Seuil.

Guebel Daniel (2009), Mis escritores muertos, Buenos Aires: Mansalva.

Guebel Daniel (2009), El caso Voynich, Buenos Aires: Eterna Cadencia.

GuEBEL Daniel (novela inédita), El Absoluto.

LACOUe-LabARThe Philippe \& NANCY Jean-Luc (1978), L'absolu littéraire, Paris : Seuil.

LYOTARD Jean-François (2012), Pourquoi philosopher ?, Paris : PUF.

LIBERTELLA Héctor (1993), Las sagradas escrituras, Buenos Aires: Sudamericana.

Piglia Ricardo (2000), Formas breves, Barcelona: Anagrama.

\section{NOTAS}

1. La palabra "reclinatorio", mueble acomodado para arrodillarse y orar, abre así a una descripción en la que impera el campo léxico de la liturgia cristiana ("bendición", "altar", "más allá ") y de la elevación, o trascendencia divina ("alto", “altar", “alzar”, etc.).

2. Esta primera reconfiguración topográfica abre también al doble movimiento contradictorio y característico de instalación y desestabilización de la escena genérica autobiográfica a lo largo de la obra.

3. Una fascinación que recuerda el propio devenir inmortal del narrador fascinado y muriendo en la estela de las sombras inmortales de La invención de Morel.

4. En Las sagradas escrituras, el autor habla más precisamente del trato del escritor argentino con la tradición, los monstruos y fantasmas que lo acosan "reaparec[iendo] una y otra vez, con una novela futura debajo del brazo". Escribe así: "Alguien dice, por ejemplo, que sólo puede sentarse a escribir cuando empieza a leer con ganas a Manuel Puig.” (Libertella: 237)

5. Como si se detuviera definitivamente en ese punto en que el filósofo, por temor a despertar en las tinieblas de la vigilia y de la razón, había pensado por un segundo seguir "conspira[ndo] con esas gratas ilusiones para gozar más largamente de su engaño". (Descartes: 4) 
6. Un conocimiento muy superficial del campo literario argentino de los treinta últimos años bastaría, fuera de toda referencia extratextual biográfica precisa, para hacer de Daniel Guebel, el autor real de Mis escritores muertos (al que acompaña en este relato, como en otros, la sombra del escritor real Sergio Bizzio) el predicado del pronombre posesivo " $m i s$ "...

7. El tema del homenaje se impone a través del título temático-literal de esta obra en primera persona.

8. "Gradualmente se vio (como nosotros): Aprisionado en esta red sonora / de Antes, Después, Ayer, Mientras, Ahora / Derecha, Izquierda, Yo, Tú, Aquellos, Otros." (Borges: 263).

9. Retomamos aquí la expresión utilizada por J.L. Nancy y P. Lacoue-Labarthe en El absoluto literario para designar el momento en que la literatura empieza a producirse produciendo su propia teoría, la clausura del absoluto especulativo de la literatura que se abriría, según los autores, con el romanticismo alemán de Iena.

10. Volveremos sobre la importancia de los personajes femeninos como figuras alegóricas de la Verdad y el movimiento femenino y seductor del velo en la revelación del misterio del Tandilito.

11. “consagración", “sacrificar", "credo", "revelación", "mística”, etc. (Guebel: 12-15)

12. En su exégesis de "La Forma", el narrador ensalza el formalismo de la narración valiéndose de la metáfora del cuerpo humano ("el argumento de una historia es su piel; el tema es la musculatura y su grasa; la estructura del relato forma la red de órganos internos") apuntando de manera contradictoria a la trascendencia del "sistema esquelético" e "inerte" de la literatura a través de los términos de " dedicación", "consagración" que califican el arte de narrar de un artista que ha de "sacrific[arlo] todo a su $\operatorname{arte}^{\prime \prime}$ (p. 15).

13. La idea de una literatura apocalíptica que se encargaría de revelar la verdad del mundo y el sentido de la existencia es inseparable de la refutación, por parte del narrador, de la teoría del iceberg y de su poética teleológica de la "revelación" de una historia o de un sentido oculto. Volveremos sobre el efecto siempre deceptivo de la revelación y de la contradictoria puesta en práctica de la teoría del iceberg por el narrador de Mis escritores muertos.

14. Es lícito pensar que la ausencia de firma del narrador-escritor constituye también una hipóstasis y una construcción en abismo de la propia instancia autorial: señalemos aquí que la contradicción entre la desaparición anhelada de un estilo identificable y la ambición contraria de subsumir todos los estilos en la misma firma -propuesta expresada por Guebel en la nota final de su novela El caso Voynich- imprime sin duda el peculiar movimiento de una escritura autobiográfica haciéndose y deshaciéndose al compás de esta tensión discordante. Véase también: Guebel, El caso Voynich, p. 117.

15. En el relato de Diotima (El banquete, 203-204a), Eros no es "ni mortal ni inmortal": su padre es el dios Poros, y su madre, Penia, es mortal y mendiga. A la vez vida o plenitud (Poros) y muerte e indigencia (Penia), figura el deseo en tanto presencia y ausencia (ausencia de la presencia e inversamente), y, pulsión eternamente reactualizada de vida (pues lleva en él la muerte, o la Penuria). (Lyotard: 25-27)

16. El peligro de muerte acecha al narrador en cada una de las etapas de su larga caída: "El accidente parece convencional, de comedia [...] pero lo que está ocurriendo no puede ser inocuo: me costará la vida si un fragmento de madera, por ejemplo una de las patas, se clava en mis riñones. [...] En medio segundo más, a lo sumo en uno o dos segundos, mi cuerpo se estampará contra el piso y mutis por el foro de la vida. [...] Si voy a morir -es la gran posibilidad-, lo mejor es que mi última palabra, la que precede o define mi fin, no tenga que ver con la banalidad de una pobre discusión." (Guebel: 27-30)

17. Guebel Daniel, El Absoluto, inédito.

18. "La flamme", la llama o el fuego, es una metáfora privilegiada del espíritu, y por supuesto y principalmente del espíritu divino en el Antiguo Testamento.

19. En el orden de la analogía del sol con la verdad -que caracteriza la metafísica occidental desde Platón- el sol de la evidencia es también un deslumbramiento insostenible, el punto en que la visión surge como su propia luz es también un punto ciego. 
20. Terminado el relato del recorrido en camioneta y del enigma del Tandilito, queda para el lector la sospecha de que todo no haya sido más que un sueño (más) del narrador: "Luego de esa frase, las cosas adoptaron un rumbo extraño. Posiblemente yo me quedé dormido -lo que resulta poco verosímil, teniendo en cuenta que estaba a cargo del volante. Al despertar descubro que estoy en mi cuarto de hotel." (Guebel: 53)

21. Ese desplazamiento de la rubia de personaje a actante de la enunciación no se produce mediante un cambio de nivel narrativo sino a través un cambio de voz que pasa de homodiegética ( $u$ autodiegética) a heterodiegética.

22. Edipo es el único en contestar los enigmas de la Esfinge y el enigma de la mujer violando el secreto más íntimo de Madre-naturaleza. Yocasta se ahorca y La Esfinge se despeña en el abismo que la vio surgir. (Kofman: 102)

23. En su exégesis de los textos de Freud, Sarah Kofman analiza la constitución de la mujer en objeto de estudio y curiosidad para el psicoanálisis: el pudor -debido a la represión sexual que padece en la sociedad-, es lo que legitima en última instancia la idea según la cual la mujer recelaría secretos que la cura habría de revelar, o des-velar. (Kofman: 42-52)

24. La tensión existente, en el texto de Mis escritores..., entre el silencio de la morena y la voz cantante de la rubia así como la imagen del "tejido contrapuntístico", refuerza este paralelo con el enigma de la mujer en la teoría freudiana: la mujer que permanece silente es también la que vela dos veces el secreto natural de su esencia, redoblando el artificio natural del vello púbico. La mujer tejedora (inventora del arte del tejido) y seductora. (Kofman: 52)

25. Esta digresión también retoma la oscilación característica entre lo animado y lo inerte, el alma y el cuerpo, en un doble movimiento que opone y a la vez asemeja las dos tendencias del arte contemporáneo: la exposición del alma de los escritores en el relato autobiográfico, y la exhibición de su cuerpo -piel, vísceras y órganos internos- por los artistas plásticos conceptuales. (Guebel: 50)

26. Hablando de monstruos, en este desenlace de "disoluciones y reconfiguraciones", la lectora atenta no podrá menos que preguntarse también si el alma "perspicaz y reservada" de la morena que habitaba la voz cantante (y estúpida) de la rubia, también mudó de cuerpo y de sexo...

27. En el epílogo de Mis escritores muertos, podemos leer: "Se llama por ello Uróboros y representa la unidad de todas las cosas materiales y espirituales, que no desaparecen nunca, sino que cambian de aspecto en un ciclo perpetuo de destrucción y creación. [...]"

\section{RESÚMENES}

Publicada en 2009, Mis escritores muertos de Daniel Guebel se presenta como un homenaje a dos escritores argentinos contemporáneos desaparecidos, Jorge Di Paola y Héctor Libertella. Suerte de "ficción en la fisión", esta remembranza es también una obsesiva combinatoria de la distinción y del tributo en la que se van desvelando los acordes de una voz singular. Literalmente habitado por el motivo de la desunión y de la contradicción, este relato de la persecución de lo oculto bajo la superficie de las cosas, detrás de las apariencias -el monstruo subacuático de Tandil, el enigma de la mujer-, trama también en secreto la clave de un arte de narrar. Siguiendo el hilo de la metáfora de la respiración -y su contracorriente fisiológica- trataremos de aprehender el tempo, o ritmo espiritual de una escritura cuya mecánica contradictoria encripta también el principio 
vital, la poiesie y la potentia. La unidad melódica de una escritura de la ausencia y la discordancia, de la destrucción y la generación.

Publiée en 2009, Mis escritores muertos de Daniel Guebel se présente comme un hommage à deux écrivains argentins contemporains disparus, Jorge Di Paola et Héctor Libertella. Sorte de « fiction dans la fission ", cette évocation se révèle être aussi une formidable combinatoire de la distinction et du tribut où se révèlent progressivement les accords d'une voix singulière. Littéralement habité par les motifs de la désunion et de la contradiction, ce récit de la persécution de l'invisible enfoui sous la superficie des choses, derrière les apparences - le monstre subaquatique de Tandil, l'énigme de la femme - trame aussi en secret la clé d'un art singulier du récit. Suivant le fil de la métaphore de la respiration - et son contre-courant physiologique - nous essaierons d'appréhender le tempo, ou le rythme spirituel d'une écriture dont la mécanique contradictoire chiffre aussi le principe vital, la poiesie et la potentia. L'unité mélodique d'une écriture de l'absence et de la discordance, de la destruction et la régénération.

Mis escritores muertos, by Daniel Guebel, published in 2009, pays homage to the late Jorge Di Paola and the late Hector Libertella, both contemporary Argentinian writers. A sort of "fiction in fission ", this commemoration turns out also to be an excellent combination of distinction and tribute, in which the chords of a singular voice gradually emerge. Literally possessed by the motifs of disunion and contradiction, this narrative of the persecution of the invisible that is buried beneath the surface, concealed behind appearances -the underwater monster of Tandil, the enigma that is Woman-, holds, secretly woven into it, the key to a singular narrative art. Following the thread of the metaphor of breathing in, -and its physiological counter-current- we shall endeavor to grasp the tempo, or the spiritual rhythm of a style of writing, the contradictory mechanics of which also encrypt the life blood, that is, poiesie and potentia. The melodic unity of the writing of absence and discordancy, of destruction and regeneration.

\section{ÍNDICE}

Palabras claves: Guebel, Libertella, Di Paola, tributo, cuento, poética, contradicción, desunión, deseo, mujer, enigma, secreto

Keywords: Guebel, Libertella, Di Paola, tribute, short story, poetics, contradiction, disunion, desire, woman, enigma, secret

Mots-clés: Guebel, Libertella, Di Paola, tribut, nouvelle, poétique, contradiction, désunion, désir, femme, énigme, secret

\section{AUTOR}

\section{CORINNE FERRERO}

Université de Pau et des pays de l'Adour 